\title{
Analysis of thin-film structures with nuclear backscattering and $x$-ray diffraction
}

\author{
J. W. Mayer* \\ California Institute of Technology, Pasadena, California 91109
}

K. N. $\mathbf{T u}^{\dagger}$

IBM Thomas J. Watson Research Center, Yorktown Heights, New York 10598

(Received 29 August 1973)

\begin{abstract}
Backscattering of $\mathrm{MeV}{ }^{4} \mathrm{He}$ ions and Seemann-Bohlin $\mathrm{x}$-ray diffraction techniques have been used to study silicide formation on $\mathrm{Si}$ and $\mathrm{SiO}_{2}$ covered with evaporated metal films. Backscattering techniques provide information on the composition of thin-film structures as a function of depth. The glancing-angle x-ray technique provides identification of phases and structural information. Examples are given of $\mathrm{V}$ on $\mathrm{Si}$ and on $\mathrm{SiO}_{2}$ to illustrate the major features of these analysis techniques. We also give a general review of recent studies of silicide formation.
\end{abstract}

\section{INTRODUCTION}

The formation of silicide layers has played an important role in integrated circuit technology. Ohmic contacts and barriers on $\mathrm{Si}$ are formed by evaporating a metal layer $(\mathrm{Pd}, \mathrm{Pt}, \mathrm{Ti}, \ldots)$ on $\mathrm{Si}$ and by subsequent heating to form the metal-silicide. ${ }^{1}$ We have utilized backscattering techniques with $\mathrm{MeV}$ He ions to study the kinetics of the silicide growth and glancingangle $x$-ray diffraction techniques to identify the phases that are formed. This paper is a review of the capabilities of these analytical techniques and of the results obtained in our and other laboratories, concerning metal-silicon interactions.

The process steps of evaporation and heat treatment are simple and easily adapted to device production. The factors which govern the silicide formation are more complex. Of the 12 metal-silicon systems studied in some detail, ${ }^{2-17}$ all have between three and seven silicide structures identified in bulk samples. ${ }^{18-21}$ In thin-film structures, typically only one and in a few cases two silicide phases are formed. The lowest eutectic temperatures given in the phase diagrams range between 740 and $1400^{\circ} \mathrm{C}$, yet the silicides form in thin-film samples at temperatures between 200 and $800^{\circ} \mathrm{C}$. In most cases the formation occurs at temperatures of about one-third to one-half the melting point (in ${ }^{\circ} \mathrm{K}$ ). This is a sure sign that solid-solid rather than solid-liquid reactions are involved. It has recently been found that silicide layers are formed during heat treatment of metal layers on $\mathrm{SiO}_{2}{ }^{11,16}$ Usually, a different phase is formed and the reaction temperature is $100-200^{\circ} \mathrm{C}$ higher than for the metal-silicon systems.

From an operational standpoint it is of interest to determine the temperatures at which silicide growth occurs, the growth rates, the identity of the phases, their stability, and the influence of the interface conditions (presence of oxide layer). These aspects are of concern in integrated circuit technology and can be answered directly by the combined use of $\mathrm{MeV} \mathrm{He}$ backscattering and glancing-angle $\mathrm{x}$-ray diffraction techniques. The underlying problem is to determine what factors govern the nucleation and growth of the silicide. Some insight can be gained by measuring the kinetics of the process and determining which species, $\mathrm{Si}$ or metal, diffuses through the silicide layer. Again, backscattering techniques can be used.

\section{ANALYTICAL TECHNIQUES}

\section{A. $\mathrm{MeV}{ }^{4} \mathrm{He}$ Ion Backscattering}

This technique has been described in detail previously ${ }^{22-23}$ and will be discussed only briefly. As shown in Fig. 1, the sample is mounted in a chamber (modest vacuum requirements, $\sim 10^{-5}-10^{-6}$ Torr) and bombarded with monoenergetic $\mathrm{He}$ ions (typically at 2 $\mathrm{MeV}$ ) at current levels of $20-50 \mathrm{nA}$ over about a $2 \times 2-\mathrm{mm}$ area. Only a small fraction of the incident particles are backscattered so the beam is to first order not attenuated. The silicon surface barrier detector produces a voltage pulse that is proportional to the energy of the individual backscattered $\mathrm{He}$ ions. The pulses are amplified and stored in a pulse-height

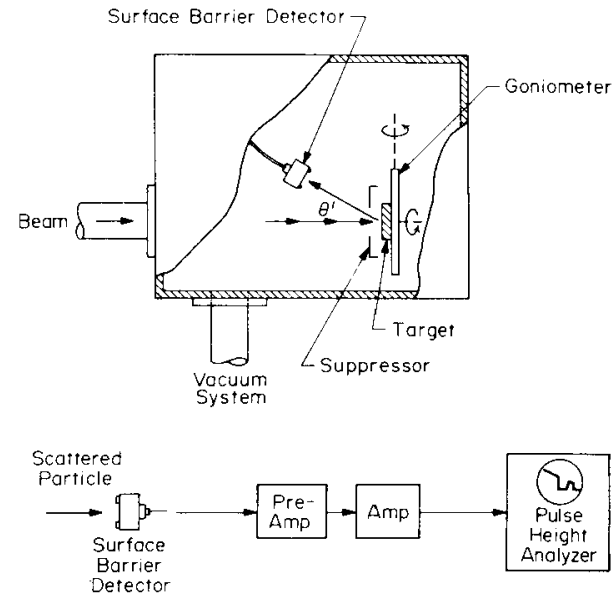

FIG. 1. Schematic diagram of the sample chamber used in backscattering measurements. 
analyzer, and at the end of the analysis (generally 15-30 min) the energy spectrum of backscattered particles is displayed.

The energy of particles scattered from surface atoms is determined by the mass of the target atom through scattering kinematics $K$ (billiard-ball kinetics), the number of particles backscattered by the scattering cross section $\sigma$ [Rutherford scattering with $\sigma \propto(Z / E)^{2}$ in this energy region], and the energy loss in traversing the film by stopping cross section $\epsilon$. All these parameters, $K, \sigma$, and $\epsilon$, are well known with the major uncertainty in the stopping cross section $\epsilon$ where the values are generally established within $\pm 5 \% .{ }^{24}$ Consequently, these backscattering spectra give directly and quantitatively the distribution of elements as a function of depth in the target. In effect it provides mass-sensitive depth microscopy.

It should be noted that the depth scale is determined by the number of target atoms $/ \mathrm{cm}^{2}$ in an incremental layer, not by the thickness of the layer. Cast in other terms, the density of a thin film can be determined from measurement of the number of target atoms $/ \mathrm{cm}^{2}$ (or from the difference in energy between particles scattered from the front and rear surface of a film) and from an independent measurement of the film thickness by interferometric techniques. For simplicity, the film thicknesses are usually given in dimensions of $\AA$ with the assumption of bulk density.

The advantages of backscattering then are (i) quantitative measurement of composition, (ii) nondestructive determination of depth profiles, and (iii) simple and direct interpretation of experimental data. The measurements themselves are quite easy to perform.

Some of these features are shown in Fig. 2, which gives backscattering spectra for an evaporated layer of $\mathrm{V}$ on $\mathrm{Si}$ before and after heat treatment. For the as-deposited case (dashed line), the broad peak is the component of the spectrum due to particles backscattered from $V$. The measured energy difference between particles scattered from the front surface and the back surface of the $V$ layer-i.e., the width of the peak-is $300 \mathrm{keV}$, which corresponds to $2.24 \times 10^{18} \mathrm{~V}$ atoms $/ \mathrm{cm}^{2}$ or a thickness of $3100 \AA$ if bulk density is assumed. After heat treatment, a step appears in both the $\mathrm{V}$ and $\mathrm{Si}$ portions of the spectrum. This step

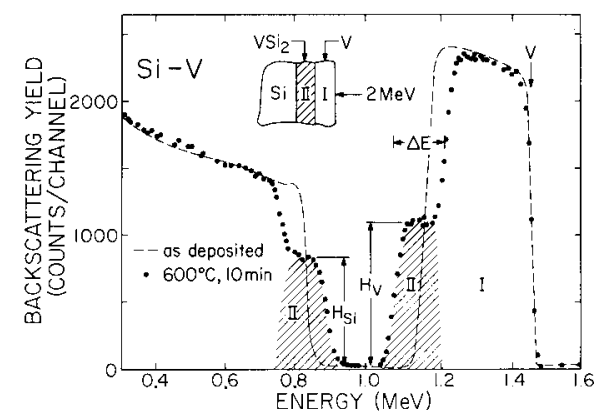

FIG. 2. Backscattering spectra for $2-\mathrm{MeV}{ }^{4} \mathrm{He}$ ions incident on Si sample covered with $3100 \AA$ of $\mathrm{V}$ and heat treated at $600^{\circ} \mathrm{C}$ Data from Kraütle et al. (Ref. 16).

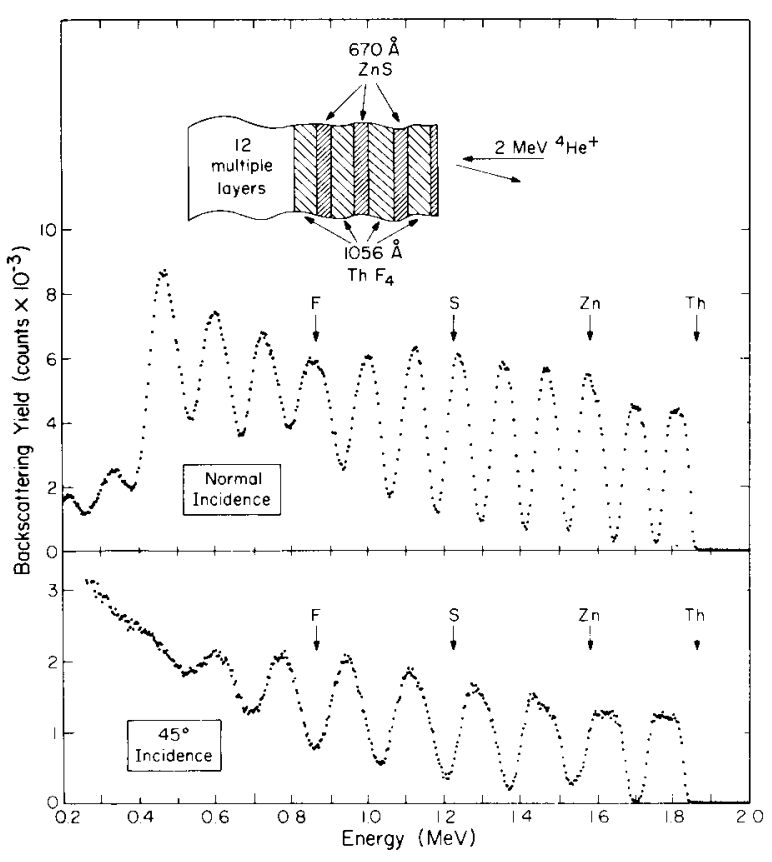

FIG. 3. Backscattering spectra for $2-\mathrm{MeV}{ }^{4} \mathrm{He}$ ions incident on a multilayer antireflecting coating on quartz substrate. There are 12 layers of $\mathrm{ThF}_{4}$ separated by layers of $\mathrm{ZnS}$ (sample supplied by R. Honig, RCA).

corresponds to the formation of a silicide layer. The composition can be determined from the ratio of the heights, $H$, of the $\mathrm{V}$ and $\mathrm{Si}$ steps, here 1.35 , when corrected for the ratio of scattering cross sections, $\sigma_{\mathrm{Si}} / \sigma_{\mathrm{V}}=0.36$. This gives a $\mathrm{V} / \mathrm{Si}$ ratio of 0.485 which must be corrected upwards by a factor of 1.04 because of the differences in stopping cross section for particles scattered from $\mathrm{V}$ and from $\mathrm{Si}$. This result shows that in the layer there are two $\mathrm{Si}$ atoms for every $\mathrm{V}$ atom, an indication that the compound $\mathrm{VSi}_{2}$ is formed. How ever, positive identification requires structural data which are provided by x-ray diffraction (see Sec. II B).

The thickness $t$ of the composite layer is determined from the energy width $\Delta E$; here $\Delta E=140 \mathrm{keV}$. In assuming bulk density this gives a thickness of $1700 \AA$. The growth kinetics of the composite layer can be found from the time dependence of $\Delta E$ for various heat treatment cycles.

The fact that the edges of the steps are sharp in Fig. 2 demonstrates that the layer is uniform in thickness over the dimensions of the beam. Laterally, nonuniformities introduce a broadening in the edges and hence uncertainties in thickness determination. If local cracking or flaking of the film occurs during thermal processing, backscattering spectra are misleading. Hence, one should also examine the lateral uniformity by optical microscopy or preferably by use of a scanning electron microscope.

Backscattering spectra are simple to interpret when there are only a few elements in the target. For multilayer targets, the spectra can be complex. Figure 3 shows spectra for normal incidence and $45^{\circ}$ beam-totarget orientation for a 12-layer $\mathrm{ThF}_{4}-\mathrm{ZnS}$ reflective coating. The distinct peaks reflect the $\mathrm{Th}$ in the 12 


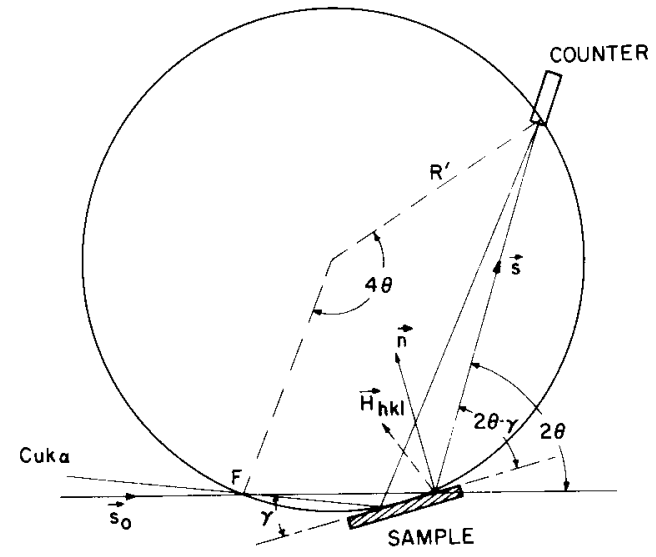

FIG. 4. Schematic diagram of the geometry of Seemann-Bohlin diffraction configuration.

$\mathrm{ThF}_{4}$ layers, and the valleys show the position and thickness of the $\mathrm{ZnS}$ layers. The contribution from the $\mathrm{Zn}, \mathrm{S}$, and $\mathrm{F}$ cannot directly be seen in the spectra. The arrows indicate their energy position if located at the surface. The two peaks at the highest energy are flat topped and have sharp edges indicated well-defined layers of uniform composition. At lower energies (greater depths in the multilayer structure) the broadening of the edges reflect both a loss of depth resolution due to energy straggling and interference from lowermass elements.

\section{B. Seemann-Bohlin X-Ray Diffraction}

The Seemann-Bohlin configuration for structural analysis of thin films is basically a glancing-angle $\mathrm{x}$-ray diffraction using a focused beam with a fixed angle of incidence. It is known that to study the structure of a polycrystalline thin film of thickness of the order of $10^{2}-10^{4} \AA$ is difficult by conventional x-ray techniques because there is not much material for scattering. However, scattered beams can be strengthened by increasing the path of the $x$-ray in the film by the use of a fixed incident beam at a near-grazing incidence, and we note that such a fixed incident beam can be obtained in a diffractometer based on the focusing Seemann-Bohlin configuration but not on the conventional Bragg-Brentano configuration. ${ }^{25}$ In the focusing Seemann-Bohlin configuration (see Fig. 4) the specimen is placed on the circumference of the diffraction circle and the angle of incidence is fixed and can be made as small as a few degrees; for example, an incident angle of $6.4^{\circ}$ in this case will increase the length of the path of the beam in the specimen to about nine times its thickness. The specimen, the focus $F$ of the monochromatic incident beam, and the focus of the diffracted beams all lie ideally on the circumference of the diffraction circle. Based on this principle, Feder and Berry ${ }^{26}$ have designed and built an $\mathrm{x}$-ray diffractometer with a diffraction circle of 20-in. diameter. An important feature of the diffractometer is that it employs a pyrolytic graphite monochromator crystal to produce a high-intensity monochromatic $\mathrm{Cu} \mathrm{K}_{\alpha}$ radi- ation as the incident beam. The intensity obtained from the graphite crystal is 15 times greater than that obtained from a LiF crystal. Also, a circular helium chamber of 18-in. diam is interposed in the path of the diffracted beams to reduce the atmospheric absorption.

The performance of the diffractometer has been discussed elsewhere. ${ }^{26} \mathrm{We}$ mention briefly here that it has detected a polycrystalline copper film of $150 \AA$ and showed a precision lattice parameter measurement of a number of $1000-\AA$ nickel films with an accuracy of $\pm 0.0001 \AA$-i.e., 1 part in 35000 . In addition to the high sensitivity of detecting phases, the SeemannBohlin diffraction allows convenient structural analysis of grain size, biaxial strain, and the distribution of pole densities. This is because its reciprocal lattice vector $\mathrm{H}$ of Bragg diffractions is not parallel to the normal $\mathrm{n}$ of the film surface but rather makes inclination angles with the normal. The angle increases with the order of the reflections. Thus each reflection measures in a different direction the lattice parameters, the size, and the total amount of coherently diffracted regions. It is clear that this type of diffractometer can deliver a great deal of structural information of polycrystalline thin films. We should note that single-crystal films are not suitable for a Seemann-Bohlin diffractometer and the diffraction patterns may show no peaks at all. This may be regarded as advantageous for a polycrystalline film on a single-crystal substrate such as a metal film on a $\mathrm{Si}$ wafer since we do not need to worry about the interference of $\mathrm{Si}$ reflections.

It seems that for a structural study of thin films of thickness around $1000 \AA$ and less we can use transmission electron microscope, for films thicker than several microns we can use conventional $x$-ray equipment, and for films in between we can use a SeemannBohlin-type $x$-ray diffractometer.

The diffractometer is expected to be very powerful in the investigation of the interaction in thin films ${ }^{27}$ because the reaction products can be identified by their $x$-ray reflections very early in the diffusion cycle. Figure 5 shows the $x$-ray pattern of a sample of $3200 \AA$ of $\mathrm{V}$ on a Si wafer that has been heat treated at $800^{\circ} \mathrm{C}$ for $15 \mathrm{~min}$. The pattern was obtained by scanning the sample with $\mathrm{Cu} K_{\alpha}$ radiation at steps of $0.15^{\circ}$

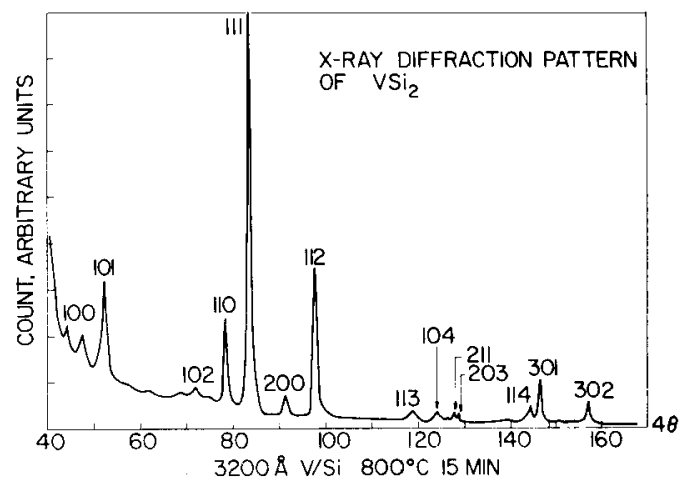

FIG. 5. X-ray diffraction pattern of V-Si heat treated at $800^{\circ} \mathrm{C}$ for $13 \mathrm{~min}$ in an oxygen-free furnace. The vanadium film had a thickness of $3200 \AA$. Reflections of $\mathrm{VSi}_{2}$ are indexed. 
increment and with a counting time of $30 \mathrm{sec}$ at each step. The peaks have been indexed as reflections of $\mathrm{VSi}_{2}$ according to ASTM Card No. 13-260. In this sample, the x-ray diffraction data confirm the composition analysis determined from backscattering data (Fig. 2).

\section{ANALYSIS OF SILICIDE FORMATION}

\section{A. General Precautions}

One of the objectives of this type of analysis is to determine the growth kinetics. It is a course fraught with peril, and sample preparation is the dominant factor. There are three areas which must be considered : interface, contamination, and stress.

1. Interface. The native oxide layer on silicon surfaces must be considered when preparing samples. It has been shown that thin oxide layers significantly retard silicide formation. ${ }^{6}$ The thickness of a native oxide layer is markedly different for different wafer orientations, ${ }^{28}$ and hence sample orientation plays a role. Soaking in $\mathrm{HF}$ and then rinsing prior to mounting in the evaporation chamber does not guarantee an oxide-free surface. One approach is to sputter clean the surface and then to deposit the metal layer without breaking vacuum. Although this creates reproducible surface conditions, the silicon surface is heavily damaged and the sputtering gas is retained in the surface layer. ${ }^{29}$

2. Contamination. Oxygen and other ambient contaminations can be introduced during deposition or thermal processing. Trace inclusions of oxygen are hard to detect by backscattering techniques, although relatively massive concentrations $(10-20$ at. $\%$ ) can be readily identified. There has not been a positive correlation of film contamination with retardation of silicide growth; however, preliminary data suggest that this may be a real problem. ${ }^{30}$

3. Stress. One of the most difficult factors to overcome is film cracking or peeling due to stress created during thermal processing. Backscattering measurements on such samples are unreliable. Film peeling is often enhanced for thicknesses greater than a few thousand angstroms. In some cases, this problem can be alleviated by maintaining an oxide-free interface or depositing the film at elevated temperatures.

There is of course the polycrystalline nature of the deposited and reacted film that should be considered. Grain size and grain boundary diffusion may be important particularly at low process temperatures $\left(T \lesssim 400^{\circ} \mathrm{C}\right)$. These problems have not been properly addressed in silicide formation, but are known to occur in metal-metal thin-film studies. At higher temperatures, bulk diffusion will probably dominate over grain boundary effects.

\section{B. An Example: V-Si System}

Backscattering analysis has been applied to nearly a dozen silicide systems, two of which $\left(\mathrm{Pd}-\mathrm{Si}^{3,6,9,10,12-14}\right.$ and $\left.\mathrm{Hf}-\mathrm{Si}^{7,8}\right)$ have been studied in detail. We have

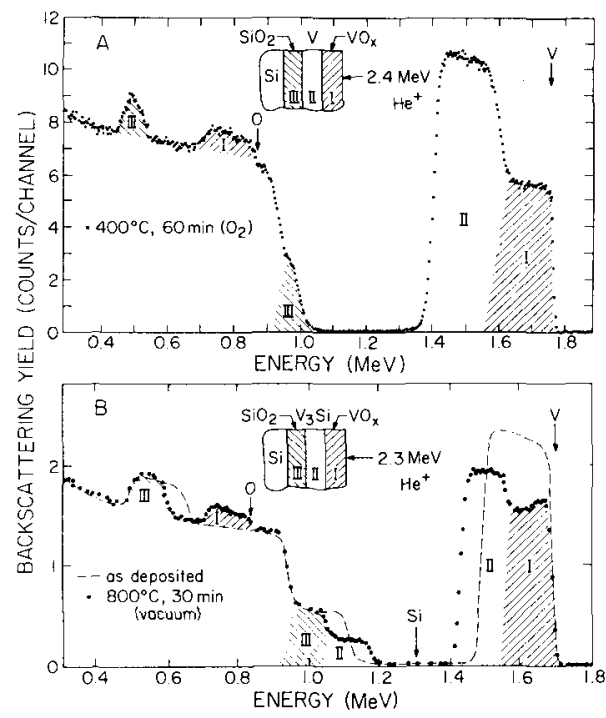

FIG. 6. Backscattering spectra for 2.3-MeV ${ }^{4} \mathrm{He}$ ions incident on a $\mathrm{Si}$ sample with a thermally grown layer of $\mathrm{SiO}_{2}$ covered with an evaporated layer of $\mathrm{V}$. (a) heat treatment at $400^{\circ} \mathrm{C}$ for $60 \mathrm{~min}$ in $\mathrm{O}_{2}$ ambient, and (b) heat treatment at $800^{\circ} \mathrm{C}$ for 30 min in vacuum. Data from Kraütle et al. (Ref. 16).

chosen the vanadium-silicide system as an example because the problems are still fresh (as the study has not been completed), and also we can consider aspects of silicide formation on $\mathrm{SiO}_{2}$. Our work ${ }^{11,16}$ with $\mathrm{Ti}$, $\mathrm{Nb}$, and $\mathrm{V}$ deposited on $\mathrm{SiO}_{2}$ shows that silicides are formed but at higher process temperatures than for $\mathrm{Si} /$ metal systems and that the silicide is metal rich.

Figure 6 shows backscattering spectra for $\mathrm{V}$ films deposited on $\mathrm{SiO}_{2}{ }^{30}$ For the as-deposited case [dashed line in Fig. 6(b)], the spectrum shows the contribution from $\mathrm{V}$ and $\mathrm{Si}$ in the oxide layer and substrate, and from oxygen in the oxide layer. The oxygen contribution is superimposed on that from the underlying $\mathrm{Si}$ substrate. The arrows indicate the energy position of these elements when at the surface. After heat treatment in oxygen at $400^{\circ} \mathrm{C}$, there is a change in the composition of the sample. Oxygen is now present at the outermost layers (I) as is evident in Fig. 6(a) from the step in the $\mathrm{V}$ component and the appearance of a broad mesa whose high-energy edge corresponds to the position of oxygen at the surface. There is not a significant amount of oxygen in underlying $\mathrm{V}$ layer (II) as is indicated by the following: (a) The height of the $\mathrm{V}$ portion of the spectrum (layer II) coincides with the as-deposited case; and (b) there is a dip in the oxygen component of the spectrum in the region between that from oxygen in $\mathrm{SiO}_{2}$ (III) and in vanadium oxide (I).

The composition of the vanadium oxide can be estimated from the ratio of the heights of vanadium and oxygen components in region $I$ to be close to that of $\mathrm{V}_{2} \mathrm{O}_{5}$. Positive identification was made from glancingangle $x$-ray diffraction data (Fig. 7). The peaks correspond to those indexed for $\mathrm{V}_{2} \mathrm{O}_{5}$.

With reference again to Fig. 6 , it is evident that there is a dramatic change in composition when a similar sample is heated to $800^{\circ} \mathrm{C}$ in vacuum. The composition of the layers can be deduced from the spectrum to 


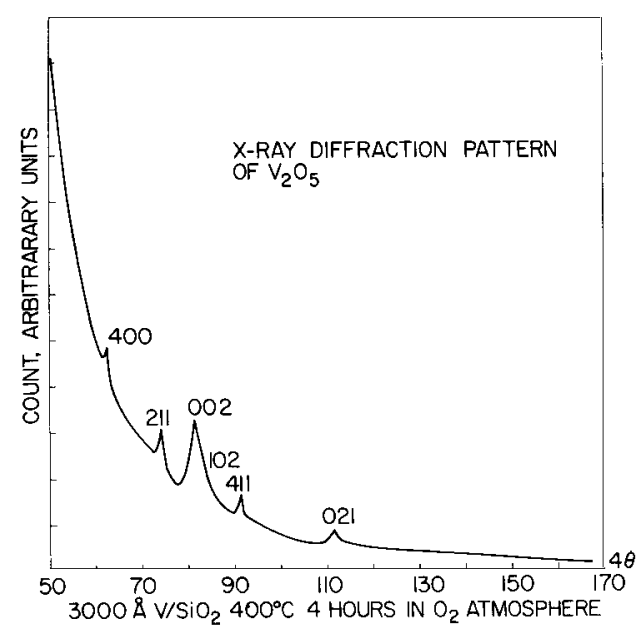

Fig. 7. X-ray diffraction pattern of $\mathrm{V}-\mathrm{SiO}_{2}$ heat treated at $400^{\circ} \mathrm{C}$ for $4 \mathrm{~h}$ in an atmosphere of $\mathrm{O}_{2}+\mathrm{H}_{2} \mathrm{O}$. The vanadium film had a thickness of $3000 \AA$. Reflections of $\mathrm{V}_{2} \mathrm{O}_{5}$ are indexed.

show the following: for layer $I$, approximately equal amounts of vanadium and oxygen with no appreciable concentration of $\mathrm{Si}$; for layer $I I$, three times as much $\mathrm{V}$ as $\mathrm{Si}$ and no appreciable oxygen; for layer $I I I, \mathrm{SiO}_{2}$ but of reduced thickness. The amount of oxygen removed from the initial thickness of $\mathrm{SiO}_{2}$ (III) corresponds to the amount added to the vanadium oxide layer (I), which indicates that the amount of oxygen in the composite layers is conserved.

The $\mathrm{x}$-ray diffraction data for this sample coincide with those given by $\mathrm{Tu}$ et $a l .{ }^{11}$ for a similar sample and show the presence of $\mathrm{V}_{3} \mathrm{Si}, \mathrm{V}_{5} \mathrm{Si}_{3}$, and $\mathrm{V}_{2} \mathrm{O}_{5}$. The major feature is the predominance of $\mathrm{V}_{3} \mathrm{Si}$ for this sample, whereas $\mathrm{VSi}_{2}$ is formed in the $\mathrm{V}$-Si samples.

There are two unusual features in this comparison between backscattering and $\mathrm{x}$-ray diffraction data. Backscattering data indicate a $1: 1$ ratio of $\mathrm{V}$ to $\mathrm{O}$, and diffraction data indicate $\mathrm{V}_{2} \mathrm{O}_{5}$. This may be due to the fact that the $\mathrm{V}_{2} \mathrm{O}_{5}$ eutectic is at a lower temperature ${ }^{18}$ then the $800^{\circ} \mathrm{C}$ process temperature. We suggest that oxygen dissolves in the vanadium at the process temperature and then the $\mathrm{V}_{2} \mathrm{O}_{6}$ nucleates as crystallites imbedded in a matrix of vanadium when the sample cools below the eutectic. However, the average $\mathrm{V} / \mathrm{O}$ ratio over the entire vanadium-oxide film thickness could be near unity as indicated by backscattering data.

TABLE I. Comparison of silicide formation in thin metal films deposited on $\mathrm{Si}$. The numbers in parenthesis indicate the temperature at which silicide formation was observed by backscattering techniques. The asterisks indicate silicides that have been identified by diffraction techniques.

\begin{tabular}{cccc}
\hline \hline IV B & $\mathrm{V} \mathrm{B}$ & $\mathrm{VI} \mathrm{B}$ & $\mathrm{VIII}$ \\
\hline $\mathrm{Ti}^{*}$ & $\mathrm{~V}$ & $\mathrm{Cr}$ & $\mathrm{Ni}$ \\
$\mathrm{TiSi}_{2}\left(600^{\circ} \mathrm{C}\right)$ & $\mathrm{VSi}_{2}\left(600^{\circ} \mathrm{C}\right)$ & $\mathrm{CrSi}_{2}\left(450^{\circ} \mathrm{C}\right)$ & $\mathrm{NiSi}_{2}\left(600^{\circ} \mathrm{C}\right)$ \\
$\mathrm{Zr}$ & $\mathrm{Nb}$ & $\mathrm{Mo}$ & $\left.\mathrm{Pd}^{*} \mathrm{C}\right)$ \\
$\mathrm{ZrSi}_{2}\left(700^{\circ} \mathrm{C}\right)$ & $\mathrm{NbSi}_{2}\left(650^{\circ} \mathrm{C}\right)$ & $\mathrm{MoSi}_{2}\left(1200^{\circ} \mathrm{C} ?\right)$ & $\mathrm{Pd}_{2} \mathrm{Si}\left(200^{\circ} \mathrm{C}\right)$ \\
$\mathrm{Pfi}^{*}$ & $\mathrm{Ta}$ & $\mathrm{W}$ & $\left.\mathrm{Pt}^{\circ} \mathrm{C}\right)$ \\
$\mathrm{HfSi}_{\left(550^{\circ} \mathrm{C}\right)}$ & & $\mathrm{WSi}_{2}\left(650^{\circ} \mathrm{C}\right)$ & $\mathrm{Pt}_{2} \mathrm{Pi}^{*}\left(200^{\circ} \mathrm{C}\right)$ \\
$\mathrm{HfSi}_{2}\left(750^{\circ} \mathrm{C}\right)$ & & & \\
\hline \hline
\end{tabular}

The other question concerns the location of the $\mathrm{V}_{5} \mathrm{Si}_{3}$ identified in $\mathrm{x}$-ray diffraction. Backscattering data ${ }^{16}$ do not show appreciable amounts of $\mathrm{Si}$ near the surface [region I in Fig. 6(b)] and the spectrum height ratio for the silicide layer (region II) corresponds to $\mathrm{V}_{3} \mathrm{Si}$. At present we suggest the $\mathrm{V}_{5} \mathrm{Si}_{3}$ is located near the interface between regions $\mathrm{I}$ and $\mathrm{II}$.

This example clearly shows the drastic effect that a thin oxide can have on both growth kinetics and silicide composition. In this case, the metal-rich silicide is of interest in its own right as a superconductor with a transition temperature of $17^{\circ} \mathrm{K} . .^{11}$

\section{SILICIDE FORMATION}

In this section we will review experimental data on silicide formation from the standpoint of structure, thermodynamics, and kinetics. We also include some speculations and suggestions for future work. Table I gives a general impression of results obtained, and more details are given in Table II.

\section{A. Structure}

The typical silicide which is formed with metal-Si interaction is the phase which is most rich in $\mathrm{Si}-\mathrm{i}$.e., $\mathrm{PtSi}$ and $\mathrm{CrSi}_{2}$. This is the end point which one expects from an equilibrium point of view. There should be two phases, $\mathrm{Si}$ and the most $\mathrm{Si}$ rich silicide. It is surprising that more phases do not appear, as one would expect all phases to be present during the reaction stage. Indeed, intermediate phases $\left(\mathrm{Pd}_{2} \mathrm{Si}, \mathrm{Pt}_{2} \mathrm{Si}, \mathrm{HfSi}\right.$, and $\mathrm{NiSi}$ ) have been detected in a few systems. Other phases may be present, but their extent is determined from kinetic considerations of diffusion rate and nucleation. Kidson ${ }^{32}$ had earlier pointed out that if the rate constants of diffusion in a given phase are small the phase layer may be too thin to be detected.

The microstructure of $\mathrm{HfSi}, \mathrm{HfSi}_{2}, \mathrm{VSi}_{2}, \mathrm{PtSi}$, and $\mathrm{Pd}_{2} \mathrm{Si}$ has been measured by x-ray diffraction. As a first approximation, the grain size of the silicide is about the same as that of the deposited metallic film $(\sim 200$ $500 \AA$ ). There have not been serious attempts to measure strain in the silicide layer and its dependence on heat treatment temperature. This is clearly one area that should be explored further.

Even though the crystal structure of most silicides are different from $\mathrm{Si}$, they tend to show some preferred orientation. The most striking case is $\mathrm{Pd}_{2} \mathrm{Si}$, which has been shown by both reflection-electron diffraction and $\mathrm{MeV}{ }^{4} \mathrm{He}^{+}$channeling techniques to grow epitaxially on $\langle 111\rangle \mathrm{Si}^{10,12-14}$ In this case, the hexagonal basal plane of $\mathrm{Pd}_{2} \mathrm{Si}$ matches quite well with the $\langle 111\rangle$ Si structure. Similar considerations of lattice matching suggest that $\mathrm{NiSi}_{2}, \mathrm{CoSi}_{2}$, and $\mathrm{FeSi}_{2}$ may also form epitaxially. This conclusion has not been tested and is an obvious area for further study.

\section{B. Thermodynamics}

Silicide formation energies have been tabulated ${ }^{33}$ for the following four systems: Mo-Si, Ta-Si, Ti-Si, and 
TABLE II. Silicide formation.

\begin{tabular}{|c|c|c|c|c|c|c|c|c|}
\hline \multirow[b]{2}{*}{ Metal $^{\mathrm{a}}$} & \multirow[b]{2}{*}{ Phases } & \multirow[b]{2}{*}{ Structure } & \multicolumn{3}{|c|}{ Backscattering } & \multirow[b]{2}{*}{$T_{\text {melt }}\left({ }^{\circ} \mathrm{C}\right)$} & \multirow{2}{*}{$\frac{T_{\text {obs }}(\mathrm{K})}{T_{\text {melt }}(\mathrm{K})}$} & \multirow[b]{2}{*}{ Reference } \\
\hline & & & Phase & $T_{\text {obs }}\left({ }^{\circ} \mathrm{C}\right)$ & Kinetics & & & \\
\hline $\mathrm{Ti}(3)$ & $\begin{array}{l}\mathrm{Ti}_{5} \mathrm{Si}_{3} \\
\mathrm{TiSi} \\
\mathrm{TiSi}_{2}\end{array}$ & $\begin{array}{l}\text { hexagonal } \\
\text { orthorhombic } \\
\text { orthorhombic (C49) }\end{array}$ & $\mathrm{TiSi}_{2}$ & 600 & $t^{t}$ & $\begin{array}{l}2120 \\
1700 \\
1540\end{array}$ & $\sim 0.5$ & 6 \\
\hline $\mathrm{Zr}(7)$ & $\begin{array}{l}\mathrm{Zr}_{2} \mathrm{Si} \\
\mathrm{ZrSi} \mathrm{ZrSi}_{2}\end{array}$ & $\begin{array}{l}\text { tetragonal } \\
\text { orthorhombic } \\
\text { orthorhombic (C49) }\end{array}$ & $\mathrm{ZrSi}_{2}$ & 700 & & $\begin{array}{l}2110 \\
2095 \\
1520\end{array}$ & $\sim 0.5$ & 15 \\
\hline Hf (5) & $\begin{array}{l}\mathrm{Hf}_{2} \mathrm{Si} \\
\mathrm{HfSi}\end{array}$ & $\begin{array}{l}\text { tetragonal } \\
\text { orthorhombic or } \\
\text { hexagonal }(\mathrm{FeB})\end{array}$ & $\mathrm{HfSi}$ & 550 & $t^{2}$ & $\begin{array}{l}2430 \\
2200\end{array}$ & $\sim 0.3$ & \\
\hline & $\mathrm{HfSi}_{2}$ & orthorhombic (C49) & $\mathrm{HfSi}_{2}$ & 750 & & 1900 & $\sim 0.5$ & 7,8 \\
\hline$V(3)$ & $\begin{array}{l}\mathrm{V}_{3} \mathrm{Si} \\
\mathrm{V}_{5} \mathrm{Si}_{3} \\
\mathrm{VSSi}_{2}\end{array}$ & $\begin{array}{l}\text { cubic }(\beta-W) \\
\text { tetragonal }(\mathrm{D} 8 \mathrm{~m}) \\
\text { hexagonal }(\mathrm{C} 40)\end{array}$ & $\mathrm{VSi}_{2}$ & 600 & th & $\begin{array}{l}2070 \\
2150 \\
1750\end{array}$ & $\sim 0.5$ & 11,16 \\
\hline $\mathrm{Nb}(4)$ & $\begin{array}{l}\mathrm{Nb}_{4} \mathrm{Si} \\
\mathrm{Nb}_{3} \mathrm{Si} \\
\mathrm{NbSi}_{2}\end{array}$ & $\begin{array}{l}\text { hexagonal } \\
\text { cubic }\left(\mathrm{Cu}_{3} \mathrm{Au}\right) \\
\text { hexagonal }(\mathrm{C} 40)\end{array}$ & $\mathrm{NbSi}_{2}$ & 650 & & & $\sim 0.5$ & 31 \\
\hline $\mathrm{Ta}(3)$ & $\begin{array}{l}\mathrm{Ta}_{2} \mathrm{Si} \\
\mathrm{TaSi}_{2}\end{array}$ & $\begin{array}{l}\text { tetragonal }\left(\mathrm{Al}_{2} \mathrm{Cu}\right) \\
\text { hexagonal }(\mathrm{C} 40)\end{array}$ & & & & $\begin{array}{l}2460 \\
2200\end{array}$ & & \\
\hline $\operatorname{Cr}(5)$ & $\begin{array}{l}\mathrm{Cr}_{3} \mathrm{Si} \\
\mathrm{CrSi} \\
\mathrm{CrSi}_{2}\end{array}$ & $\begin{array}{l}\text { cubic }(\beta-W) \\
\text { cubic }(\mathrm{FeSi}) \\
\text { hexagonal }(\mathrm{C} 40)\end{array}$ & $\mathrm{CrSi}_{2}$ & 450 & $t$ & $\begin{array}{l}1730 \\
1600 \\
1550\end{array}$ & $\sim 0.4$ & 6,15 \\
\hline Mo (3) & $\begin{array}{l}\mathrm{Mo}_{3} \mathrm{Si} \\
\mathrm{MoSi}_{2}\end{array}$ & $\begin{array}{l}\text { cubic }(\beta-W) \\
\text { tetragonal }(\mathrm{C} 11 \mathrm{~b})\end{array}$ & $\mathrm{MoSi}_{2}$ & 1200 & $t$ & $\begin{array}{l}2120 \\
2050\end{array}$ & $\sim 0.6$ & 6 \\
\hline W (2) & $\begin{array}{l}\mathrm{W}_{3} \mathrm{Si}_{2} \\
\mathrm{WSi}_{2}\end{array}$ & $\begin{array}{l}\text { tetragonal } \\
\text { tetragonal (C11) }\end{array}$ & $\mathrm{WSi}_{2}$ & 650 & $t^{3}$ & $\begin{array}{l}2350 \\
2165\end{array}$ & $\sim 0.35$ & 17 \\
\hline $\mathrm{Ni}(6)$ & $\begin{array}{l}\mathrm{Ni}_{2} \mathrm{Si} \\
\mathrm{NiSi} \\
\mathrm{NiSi}_{2}\end{array}$ & $\begin{array}{l}\text { cubic }\left(\mathrm{Cu}_{3} \mathrm{Au}\right) \\
\text { orthorhombic }(\mathrm{MnP}) \\
\text { cubic }\left(\mathrm{CaF}_{2}\right)\end{array}$ & $\begin{array}{l}\mathrm{NiSi} \\
\mathrm{NiSi}_{2}\end{array}$ & $\begin{array}{l}600 \\
800\end{array}$ & & $\begin{array}{r}1165 \\
992 \\
993\end{array}$ & $\begin{array}{l}\sim 0.7 \\
\sim 0.85\end{array}$ & 15 \\
\hline PD (3) & $\begin{array}{l}\mathrm{Pd}_{3} \mathrm{Si} \\
\mathrm{Pd}_{2} \mathrm{Si} \\
\mathrm{PdSi}\end{array}$ & $\begin{array}{l}\text { orthorhombic }\left(\mathrm{Fe}_{3} \mathrm{C}\right) \\
\text { hexagonal }\left(\mathrm{Fe}_{2} \mathrm{P}\right) \\
\text { orthorhombic }(\mathrm{MnP})\end{array}$ & $\begin{array}{l}\mathrm{Pd}_{2} \mathrm{Si} \\
\mathrm{PdSi}\end{array}$ & $\begin{array}{l}200 \\
735\end{array}$ & $t^{2}$ & $\begin{array}{r}960 \\
1330 \\
1090\end{array}$ & $\begin{array}{l}\sim 0.35 \\
\sim 0.75\end{array}$ & $\begin{array}{l}3,6,9,10,12-14 \\
14\end{array}$ \\
\hline Pt (5) & $\begin{array}{l}\mathrm{Pt}_{3} \mathrm{Si} \\
\mathrm{Pt}_{2} \mathrm{Si} \\
\mathrm{PtSi}\end{array}$ & $\begin{array}{l}\text { monogonal } \\
\text { hexagonal }\left(\mathrm{Fe}_{2} \mathrm{P}\right) \\
\text { tetragonal }\left(\mathrm{Al}_{2} \mathrm{Cu}\right) \\
\text { orthorhombic }(\mathrm{MnP})\end{array}$ & $\begin{array}{l}\mathrm{Pt}_{2} \mathrm{Si} \\
\mathrm{PtSi}\end{array}$ & $\begin{array}{l}200 \\
200\end{array}$ & $t^{\frac{1}{2}}$ & $\begin{array}{l}1100 \\
1229\end{array}$ & $\begin{array}{l}\sim 0.4 \\
\sim 0.35\end{array}$ & 4,5 \\
\hline
\end{tabular}

The number in parentheses indicates the number of phases found in bulk samples (Refs. 18-20).

$\mathrm{Zr}-\mathrm{Si}$. In the Mo-Si system, $\mathrm{MoSi}_{2}$ is the most stable phase among the Mo-silicides and was found to be the predominant phase in backscattering measurements. $\mathrm{TaSi}_{2}$ is equally stable as compared to the Ta-silicides; however, there have been no measurements of silicide formation in evaporated $\mathrm{Ta}$ films on $\mathrm{Si}$. For the Ti-Si and $\mathrm{Zr}-\mathrm{Si}$ systems, the monosilicides $\mathrm{TiSi}$ and $\mathrm{ZrSi}$ have lower free energies than the disilicides $\mathrm{TiSi}_{2}$ and $\mathrm{ZrSi}_{2}$. This suggests that before the formation of the disilicide an intermediate stage might be observed. There is no direct evidence for this, although our preliminary results ${ }^{34}$ on Ti-Si hint at the presence of an intermediate phase before $\mathrm{TiSi}_{2}$ is formed. In the $\mathrm{Hf}-\mathrm{Si}$ system, which should be analogous to $\mathrm{Zr}-\mathrm{Si}$, HfSi does form and is stable up to temperatures of $\sim 750^{\circ} \mathrm{C}$, where $\mathrm{HfSi}_{2}$ forms. In spite of these indications, we believe that there is not yet sufficient evidence to make a strong correlation with formation energy. This situation might be improved if measurements were made on the Ta-Si system and if further measurements were carried out in the Mo-Si system.
From a conventional standpoint, the stability of a phase is indicated by its melting point. This may be misleading and should not be used as a guide to predict which forms first. It is interesting to note, however, from Table II that a value of half the melting point in ${ }^{\circ} \mathrm{K}$ is a rough guide to the minimum temperature at which silicide formation has been observed. This may be too high an estimate because $\mathrm{HfSi}, \mathrm{Pd}_{2} \mathrm{Si}, \mathrm{WSi}_{2}$, and $\mathrm{PtSi}$ form at about one-third the melting point. In fact the one-third relation may be the rule rather than the exception because oxide layers at the interface will raise the formation temperature. For example, the published $\mathrm{NiSi}$ formation temperature of $600^{\circ} \mathrm{C}$ is higher than that of $300^{\circ} \mathrm{C}$ recently obtained in a separate investigation. ${ }^{34} \mathrm{We}$ suspect that the presence of the native oxide layer on $\mathrm{Si}$ might be responsible for the high temperature found for the Mo-Si system.

We can consider other aspects such as epitaxial growth that might effect stability. Hutchins and Shepala ${ }^{12}$ showed for transformation of $\mathrm{Pd}_{2} \mathrm{Si}$ to $\mathrm{PdSi}$ that higher temperatures are required on $\langle 111\rangle$-oriented 
$\mathrm{Si}$ than on $\langle 100\rangle$. On $\langle 111\rangle$-oriented $\mathrm{Si}, \mathrm{Pd}_{2} \mathrm{Si}$ shows the strongest orientation. While $\mathrm{Pd}_{2} \mathrm{Si}$ is very stable $\left(200-700^{\circ} \mathrm{C}\right), \mathrm{Pt}_{2} \mathrm{Si}$ is not and transforms to $\mathrm{PtSi}$ quite easily. One reason might be that $\mathrm{Pd}_{2} \mathrm{Si}$ is epitaxial and has a higher melting point than $\mathrm{PdSi}$, while $\mathrm{Pt}_{2} \mathrm{Si}$ does not show good epitaxy and has a lower melting point than PtSi.

For $\mathrm{Pt}_{2} \mathrm{Si}$ one finds the low-temperature (tetragonal) phase in these silicides rather than the high-temperature (hexagonal) phase; the polymorphic transition temperature is at about $700^{\circ} \mathrm{C}$. We attempted to form this hexagonal phase (which should be epitaxial on $\langle 111\rangle \mathrm{Si}$ ) by heating a sample to $750^{\circ} \mathrm{C}$ for $30 \mathrm{~min}$. Backscattering data $^{34}$ showed that $\mathrm{PtSi}\left(3 \% \mathrm{Si}\right.$ rich) rather than $\mathrm{Pt}_{2} \mathrm{Si}$ was formed. Consequently, this attempt to form a more stable phase of $\mathrm{Pt}_{2} \mathrm{Si}$ was not successful.

\section{Kinetics}

From the standpoint of kinetics, the important factors are the mechanisms for transporting metal or $\mathrm{Si}$ across the silicide layer, the activation energy, and the identity of the diffusing species. Most silicides tend to react at temperatures above $500-600^{\circ} \mathrm{C}$, except for the $\mathrm{Pd}-\mathrm{Si}$ and $\mathrm{Pt}-\mathrm{Si}$ systems, which react at temperatures as low as $200^{\circ} \mathrm{C}$. The activation energy measured for the growth process for these latter silicides is between 1.1 and $1.5 \mathrm{eV}$. This is remarkably low and opens the question of grain boundary growth. We believe, however, that bulk diffusion dominates. The structure of $\mathrm{Pd}_{2} \mathrm{Si}$ is very open, and interdiffusion is expected to be fast. Furthermore, the same activation energy was found from 100 to $700^{\circ} \mathrm{C}$, indicating that the same diffusion mechanism was involved. Also, the same growth rate is found for $\mathrm{Pd}_{2} \mathrm{Si}$ on differently oriented $\mathrm{Si}$ samples where the amount of epitaxy is different. In cases where there is less epitaxy, one anticipates more large-angle grain boundaries and increased grain boundary diffusion. All these findings support the dominance of bulk diffusion even at temperatures of $200^{\circ} \mathrm{C}$.

The other silicides react at higher temperatures, and we would expect lattice diffusion to be dominant. The activation energy for diffusion has only been measured in a few cases, but it seems to be above $2 \mathrm{eV}(2.5 \mathrm{eV}$ for $\mathrm{HfSi}, 2.9$ for $\mathrm{VSi}_{2}$, and 2.7 for $\mathrm{WSi}_{2}$ ). These values are too high for grain boundary diffusion and suggest bulk effects. One would expect to see grain boundary diffusion at lower temperatures. This could be tested by prolonged heating of a sample at temperatures below the reaction temperatures and by looking for $\mathrm{Si}$ accumulation at the free surface. This interface accumulation is often seen in backscattering studies of metal-metal interactions at low temperatures. However, no systematic studies have been made on metal-Si systems.

The growth of most silicides ( $\mathrm{HfSi}, \mathrm{Pd}_{2} \mathrm{Si}, \mathrm{Pt}_{2} \mathrm{Si}$, $\mathrm{PtSi}, \mathrm{TiSi}_{2}, \mathrm{WSi}_{2}$, and $\mathrm{VSi}_{2}$ ) has been found to follow a $(\text { time })^{\frac{1}{2}}$ relationship characteristic of a diffusiondominated process. In two cases, $\mathrm{CrSi}_{2}$ and $\mathrm{MoSi}_{2}$, a linear growth has been found. ${ }^{6}$ These systems have not been studied in detail, and we cannot speculate on the reasons for the linear growth rate. In fact, the growth kinetics of all the high-temperature silicides has not been followed in as much detail as has been done for $\mathrm{Pd}-\mathrm{Si}$ and Pt-Si. There is a need for careful kinetic studies on samples with oxide-free interfaces between metal and Si.

There is one other notable gap in all the data. With the exception of HfSi, there is no evidence to indicate whether Si or metal is the diffusing species through the silicide layer. This datum could be obtained by implanting rare gas atoms into the silicide and by using backscattering techniques to determine whether the gas atoms move toward or away from the surface. Similar studies have been made with anodic oxidation. ${ }^{35}$ For the Hf-Si system, the argon that was present as an impurity introduced during deposition served as a marker. ${ }^{7}$ The data indicated the $\mathrm{Si}$ was the diffusing species. There are practical implications. If $\mathrm{Si}$ is the diffusing species, it will leave vacancies near the $\mathrm{Si}-$ silicide interface. If these vacancies condense into voids, it leads to easy peeling of the silicide under stress.

\section{Comparison with $\mathrm{M} / \mathrm{SiO}_{2}$ Reactions}

It has recently been found that the silicide formation can occur with metals in contact with $\mathrm{SiO}_{2} \cdot{ }^{11,16}$ The behavior of $\mathrm{V}-\mathrm{SiO}_{2}$ and $\mathrm{V}-\mathrm{Si}$ has been discussed in $\mathrm{Sec}$. III $\mathrm{B}$. In the case of $\mathrm{Ti}, \mathrm{Nb}$, and $\mathrm{V}$ the silicide was the more metal-rich phase. ${ }^{16}$ At present our work is in too early a stage to give any insight into this behavior. One immediate question is to determine if the Si-rich phase forms when the $\mathrm{SiO}_{2}$ layer is consumed.

\section{SUMMARY}

This review was intended as a survey of metalsilicide formation studies where both backscattering and $\mathrm{x}$-ray diffraction measurements have been utilized. These techniques complement each other as backscattering data give composition as a function of depth and, hence, can be used to determine growth kinetics while $x$-ray diffraction gives identification of phases and structural information.

A survey of silicide formation for metal films deposited on $\mathrm{Si}$ indicates that the typical silicide that is formed is the phase that is most rich in $\mathrm{Si}$. This is the end point one expects from thermodynamic equilibrium considerations. In some cases intermediate phases have been found. On the basis of present data we have not been able to find general guidelines that can be used to predict when such an intermediate phase will occur. One striking observation is that metal-rich silicides are formed when the metal layer is deposited on $\mathrm{SiO}_{2}$ rather than on Si.

The formation temperature on the silicides is generally between one-third to one-half the silicide melting point in ${ }^{\circ} \mathrm{K}$. This shows that solid-solid rather than solid-liquid reactions are involved. The growth kinetics 
of the silicide with two exceptions have been found to follow a (time) $)^{\frac{1}{2}}$ dependence typical of diffusion-limited reactions. We believe that bulk rather than grain boundary diffusion is involved. There have not been studies to determine whether the metal or the $\mathrm{Si}$ is the diffusing species, except for the $\mathrm{Hf}-\mathrm{Si}$ case where $\mathrm{Si}$ appeared to migrate.

Our survey indicates that only the most general features of silicide formation have been studied. There are a number of areas that require further investigation. Until these are carried out, it is difficult to present an over-all picture of the factors which control silicide formation.

\section{ACKNOWLEDGMENT}

The authors acknowledge with pleasure discussions with our colleagues: C. J. Kircher and J. F. Ziegler at IBM; M-A. Nicolet, W-K. Chu, and H. Kraütle at Caltech. The authors also thank H. Kraütle for his data on $\mathrm{V}-\mathrm{Si}$ and $\mathrm{V}-\mathrm{SiO}$.

*Work supported in part by A. F. Cambridge Research Laboratories.

†Work supported in part by ARPA Contract No. F19628-73-C0006 administered by AFCRL.

${ }^{1}$ M. P. Lepselter and J. M. Andrews, in Ohmic Contacts to Semiconductors, edited by B. Schwartz (The Electrochemical Society, New York, 1969), p. 159.

${ }^{2}$ M. P. Lepselter and S. M. Sze, Bell Syst. Tech. J. 47, 89 (1969).

${ }^{3}$ C. J. Kircher, Solid-State Electron. 14, 507 (1971).

4. Hiraki, M-A. Nicolet, and J. W. Mayer, Appl. Phys. Lett. 18, 178 (1971).

${ }^{5} \mathrm{H}$. Muta and D. Shinoda, J. Appl. Phys. 43, 2913 (1972).

${ }^{6}$ R. W. Bower and J. W. Mayer, Appl. Phys. Lett. 20, 359 (1972).

${ }^{7}$ C. J. Kircher, J. W. Mayer, K. N. Tu, and J. F. Ziegler, ApplPhys. Lett. 22, 81 (1973).
${ }^{8}$ J. F. Ziegler, J. W. Mayer, C. J. Kircher, and K. N. Tu, J. Appl. Phys. 44, 3851 (1973).

${ }^{9} R$. W. Bower, R. E. Scott, and D. Sigurd, Solid-State Electron. (to be published).

${ }^{10}$ D. Sigurd, W. Van der Weg, R. Bower, and J. W. Mayer, Thin Solid Films (to be published).

${ }^{11}$ K. N. Tu, J. F. Ziegler, and C. J. Kircher, Appl. Phys. Lett. 23, 493, (1973).

${ }^{12} \mathrm{G}$. A. Hutchins and A. Shepala, Thin Solid Films (to be published).

${ }^{13}$ D. H. Lee, R. R. Hart, D. A. Kiemet, and O. J. Marsh, Phys. Status Solidi A 15, 645 (1973)

${ }^{14} \mathrm{~W}$. D. Buckley and S. C. Moss, Solid-State Electron. 15, 1331 (1972).

${ }^{15} \mathrm{~K}$. E. Sundström, S. Petersson, and P. A. Tove, Uppsala University Report No. UPTEC 73-29R (unpublished).

${ }^{16} \mathrm{H}$. Kraütle, M-A. Nicolet, and J. W. Mayer, Phys. Status Solidi A (to be published).

${ }^{17} \mathrm{~J}$. A. Borders and J. N. Sweet, private communication.

${ }^{18} \mathrm{M}$. Hansen, Constitution of Binary Alloys (McGraw-Hill, New York, 1958).

${ }^{19}$ R. P. Elliott, Constitution of Binary Alloys, First Supplement (McGraw-Hill, New York, 1965).

${ }^{20} \mathrm{~F}$. A. Shunk, Constitution of Binary Alloys, Second Supplement (McGraw-Hill, New York, 1969).

${ }^{21}$ W. B. Pearson, Handbook of Metals and Alloys (Pergamon, Oxford, 1967), Vol. 2.

${ }^{22}$ M-A. Nicolet, J. W. Mayer, and I. V. Mitchell, Science 177, 841 (1972).

${ }^{23}$ W. K. Chu, J. W. Mayer, M-A. Nicolet, T. M. Buck, G. Amsel, and F. H. Eisen, Thin Solid Films 17, 1 (1973).

${ }^{24}$ W. K. Chu, J. F. Ziegler, I. V. Mitchell, and W. D. Mackintosh, Appl. Phys. Lett. (to be published)

${ }^{25}$ B. D. Cullity, Elements of $x$-ray Diffraction (Addison-Wesley, Reading, Mass., 1956).

${ }^{26}$ R. Feder and B. S. Berry, J. Appl. Cryst. 3, 372 (1970).

${ }^{27}$ K. N. Tu and B. S. Berry, J. Appl. Phys. 43, 3283 (1972).

${ }^{28}$ W. K. Chu, E. Lugujjo, J. W. Mayer, and T. Sigmon, Thin Solid Films (to be published).

${ }^{29} \mathrm{G}$. W. Sachse, W. E. Miller, and C. Gross (unpublished).

${ }^{30} \mathrm{H}$. Kraütle, private communication.

${ }^{31} \mathrm{C}$. J. Kircher and J. F. Ziegler, private communication.

${ }^{32} \mathrm{G}$. V. Kidson, J. Nucl. Mater. 3, 21 (1961).

${ }^{33}$ R. Hultgren, R. L. Orr, and K. Kelley, Supplement to Selected Values of Thermodynamic Properties of Metals and Alloys (Department of Mineral Technology, University of California, Berkeley, Calif., 1968.

${ }^{34} \mathrm{~K}$. N. Tu and W. K. Chu (unpublished).

${ }^{35}$ F. Brown and W. D. MacKintosh, J. Electrochem. Soc. (to be published). 